\title{
Estimation of Cohort Fertility Using Parity Progression Ratio
}

\author{
Dhanendra Veer Shakya*
}

\begin{abstract}
This study attempts to analyze the levels and patterns of cohort fertility in Nepal in 2016 using data on parity progression ratios (PPRs). Simple PPRs, rather than synthetic PPRs or birth history of women, are used in this study from distribution of women by age and children ever born. Data on PPRs are used from 2016 Nepal Demographic and Health Survey to estimate cohort fertility of currently married and all women separately. Fertility is analyzed for different birth cohorts of women, specifically for birth cohorts of age groups 45-49, 20-24, 25-29, and 30-34 years, beside overall span of reproductive ages (15-49) for different purposes. The PPRs data are employed in this study in three different ways such as PPRs itself, proportion of women with at least ' $N$ ' number of children ever born (CEB), and cohort fertility rates. All three measures are implied to estimate cohort fertility of both currently married and all women separately. Fertility patterns are almost similar in all the three methods and other the measures show that the level of cohort fertility is still a little higher in Nepal, although it is declining gradually over time. The completed cohort fertility is estimated at around 4 in Nepal in 2016. The contribution of this article will be to check fertility level by applying this simple, but less common, method in estimating cohort fertility.
\end{abstract}

Keywords: Parity, parity progression ratio, cohort fertility, children ever born, reproductive ages/period/span, currently married women.

\section{Introduction}

Period fertility measures may suffer from detecting the real changes in fertility in the short term because they are affected by the timing of births i.e., tempo effect. Period measures can produce an apparent drop in fertility due to delaying of births until older age while women can end up having the same number of children as women of earlier cohorts (Sloggett, 2015). Besides, a phenomenon known as the Potter effect can suggest fertility declines in developing countries that are in fact may be unreliable in the cultures where dates of birth are not considered important. Parity progression ratios (PPRs) can be very useful when trying to establish evidence for real fertility decline as distinct from apparent decline produced by tempo effects on period measures of fertility. The PPRs are cohort measures and a rather different way of measuring fertility which are not common outside of demography but they are free of tempo effects.

* Dr. Shakya is Associate Professor at Central Department of Population Studies, Tribhuvan University, Kirtipur, Kathmandu, Nepal. 
Cohort is defined as a group of people sharing a common temporal demographic experience who are observed through time. For example, the birth cohort of certain year(s) is the people born in that year(s). Thus, cohort analysis is the observation of a cohort's demographic behaviour through life or through many periods; for example, examining the fertility behaviour of the cohort of women born in certain year or between certain years through their entire childbearing years. Whereas, period analysis is the observation of a population at a specific period of time and such analysis takes a "snapshot" of a population in a relatively short time period, usually one year (PRB, 2001). Most of the demographic measures are derived from period data, therefore, representing period rates. However, it is often useful to compare between cohort and period analyses to draw meaningful conclusions.

Ryder defined cohort analysis as "... ... quantitative description of data occurrences from the time a cohort is exposed to the risk of such occurrences" (Ryder, 1968 cited in Shryock et al., 1976). Period analysis, on the other hand, involves a quantitative description and analysis of the data for many cohorts observed during a specified time interval, such as a year. The difference between total fertility rate and completed fertility rate is the example of relationship between period and cohort analyses. The period total fertility rate for a particular year refers to several different birth cohorts to the same year, while on the other, the cohort completed fertility rate refers to a single birth cohort to many different years. Period aggregations are often referred to as 'synthetic or hypothetical cohort' represented by period data combined in such a way as to reflect hypothetical experience over a span of years or a lifetime. Thus, total fertility rate may be described as a measure for a synthetic cohort, whereas completed fertility rate is a measure of a real cohort.

Parity progression ratio (PPR) is one of the fertility measures based on cohort data and it uses the data on number of children ever born classified by birth cohort (age group) or marriage cohort of women, which are available from surveys and censuses. A PPR is simply the probability of having another child given that one has already had a certain number of children ever born. For example, if a woman has already had two births, then PPR is the probability of her having a third birth. The PPR is a measure of fertility expressed in terms of probability based on lifetime fertility experience of women at the time of survey or census.

Fertility analysis using PPRs has its own importance since it denotes the fertility level of women in the near future based on the past history of fertility of the same cohort, while on the other, period fertility represents only the current fertility levels of different cohorts and synthetic cohort measures of fertility would have certain assumptions which may or may not be met during the course of time. Besides, PPRs can be estimated for each parity progression and for each cohort which would be more meaningful in fertility analysis. 
The average number of children ever born to women aged $45-49$ years will be very similar to the cohort fertility rate. The difference being that it does not include births to emigrants or to those members of the cohort who did not survive to the date of census or survey (Newell, 1988). The cohort fertility rate for women aged 45-49 years can be estimated from data on PPRs for this age group as an arithmetic series of products of PPRs.

\section{Data and Methods}

A simple parity progression ratio (PPR) method is used in this study from the data on distribution of women by age and children ever born, i.e. birth order. Age-order-specific fertility rates or data on birth history of women are not used in this study to estimate PPR, neither synthetic period PPR, nor projected PPR derived from complicated methods are used. Apart from calculating simple PPRs, there is no any model as such is used to estimate cohort fertility in the study. Nepal Demographic and Health Survey data ,2016 on distribution of women by children ever born according to birth cohort (current age group) are used to estimate simple PPRs. Basically, two types of tabulations on distribution of women by parity are available from the survey such as distribution of currently married and all women by children ever born according to birth cohort. Both types of tabulations are used to calculate PPRs separately.

If the number of women is distributed by ascending order of parity, then the number of women is first cumulated from the bottom to give the number of women with at least ' $N$ ' number of children ever born. Then the adjacent figures are divided, the number of women with at least ' $N$ ' number of children ever born divided by the number of women with at least ' $\mathrm{N}-1$ ' number of children ever born, to obtain the probability of having next birth (i.e. $\mathrm{N}^{\text {th }}$ birth). This gives the PPR from ' $\mathrm{N}-1$ ' to ' $\mathrm{N}$ ' parity.

Parity progression ratios are calculated in this way in the study for the last age group of childbearing ages (45-49); for the most fertile three age groups in the context of Nepal, i.e. 20-24, 25-29 and 30-34 years; and the age group of overall reproductive span (15-49) for different purposes. The age group of 45-49 years is chosen as it shows the PPRs close to completed fertility. The PPRs in the age groups from 20-24 to 30-34 years will not reflect completed fertility, yet it gives more likely parity progression of certain birth orders to different birth cohorts of women, whereas, the age group of 15-49 is the overall span of reproductive period and has its own importance.

In developed countries, where two-child families are the usual norm, the PPR of second to third birth order for the age group 45-49 years is of critical importance in determining fertility levels. But in developing countries like Nepal, the same will not be appropriate. Hence, the PPR of fourth to fifth birth order is examined for the age group 45-49 years to analyze the level of fertility. However, for the age groups 20-24, 25-29 and 30-34 years, 
PPRs of 1-2, 2-3, and 3-4 birth orders are examined to determine the patterns and levels of fertility. Sloggett (2015) stated that it is perfectly possible to calculate PPRs for younger women and compare them with PPRs of similar aged women in previous surveys to try and detect a change in fertility behaviour. However, Moultrie and Zaba (2013) had stated that although more reliable conclusions can be drawn if PPRs for the same cohorts can be compared across more than one period, comparison of successive cohorts can also give information on trends in fertility.

Based on the PPRs, the proportion of women having at least ' $N$ ' number of children ever born can also be calculated. For example, the PPR from zero to the first birth gives the proportion of women having at least one child. Similarly, the PPR from zero to the first birth multiplied by the PPR from the first to the second birth gives the proportion of women having at least two children, and so on.

Again from the data on PPRs, the cohort fertility rate can also be estimated as an arithmetic series of products of PPRs. This is expressed in equation as:

Cohort Fertility Rate (CFR) $=\mathrm{a}_{0}+\mathrm{a}_{0} \mathrm{a}_{1}+\mathrm{a}_{0} \mathrm{a}_{1} \mathrm{a}_{2}+\mathrm{a}_{0} \mathrm{a}_{1} \mathrm{a}_{2} \mathrm{a}_{3}+\ldots \ldots \ldots \ldots$

where, $\mathrm{a}_{0}=$ parity progression ratio from 0 to 1 birth

$\mathrm{a}_{1}=$ parity progression ratio from 1 to 2 birth

$\mathrm{a}_{2}=$ parity progression ratio from 2 to 3 birth

$\mathrm{a}_{3}=$ parity progression ratio from 3 to 4 birth

and so on.

\section{Levels and Patterns of Parity Progression Ratios in Nepal, 2016}

The most fertile age groups of women are considered to be 20-24, 25-29 and 30-34 years in Nepal, thus, parity progression ratios for these three age groups and the last age group of reproductive period (45-49), besides for all reproductive ages (15-49), are explored in detail in this study to analyze fertility patterns in Nepal. For this purpose, PPRs are calculated separately for currently married women and all women by different birth cohorts (age groups).

\section{Parity progression ratios of currently married women}

The probability of having the fifth birth for those who have already had the fourth, among currently married women of age group 45-49 years, is about66 per cent in Nepal in 2016. It implies that two-third of currently married women in that birth cohort are likely to have their fifth birth in the near future and heading for total fertility rate of more than 4 for the cohort at the end of their reproductive ages. Thus, PPRs show still a bit higher cohort fertility for the birth cohort of age group 45-49 years. However, it is declining over times (it was $84 \%$ in $2001,80 \%$ in 2006 and $71 \%$ in 2011). 
For the birth cohort of age group 20-24 years, the probability of having the second birth for those who have already had the first is about 40 per cent (Table 1), i.e. two-fifth of currently married women are going to have their second birth at this early age group of reproductive period. The corresponding figures for the years 2001, 2006 and 2011 were 62 per cent, 55 per cent and 49 per cent respectively. The PPR for age group 25-29 years from second to third birth is about 44 per cent indicating more than two-fifth of them expecting their third birth in the near future. Thus, the third birth for little less than half of them at below 30 years of age means already more than replacement of couple and can be considered as a higher level of fertility. However, it is also declining over times (68\% in 2001, 56\% in 2006 and $50 \%$ in 2011).Similarly, for the next fertile age group of 30-34 years, PPR from third to fourth birth is about 48 per cent. At the middle of the reproductive period, almost half of them going for fourth birth also indicate somewhat high fertility level of that cohort. The corresponding figures were 71 per cent, 59 per cent and 50 per cent respectively for the years 2001, 2006 and 2011.

Table 1: Parity progression ratios of different birth cohorts (age groups) for currently married women, Nepal, 2016

\begin{tabular}{llllll}
\hline $\begin{array}{l}\text { Parity pro- } \\
\text { gression }\end{array}$ & \multicolumn{4}{l}{$\begin{array}{l}\text { Parity progression ratios of age groups } \\
\text { 20-24 }\end{array}$} & \multicolumn{2}{l}{ 25-29 } & $30-34$ & $45-49$ & $15-49$ \\
& $\begin{array}{l}\text { Birth cohorts } \\
1991-96\end{array}$ & $1986-91$ & $1981-86$ & $1966-71$ & $1966-2001$ \\
\hline $0-1$ & 0.78700 & 0.92807 & 0.97700 & 0.98800 & 0.90110 \\
$1-2$ & 0.40152 & 0.70829 & 0.86080 & 0.97267 & 0.77273 \\
$2-3$ & 0.25000 & 0.43921 & 0.55172 & 0.85328 & 0.60689 \\
$3-4$ & 0.15190 & 0.34602 & 0.47845 & 0.69390 & 0.55556 \\
$4-5$ & 0.16667 & 0.26000 & 0.42342 & 0.65554 & 0.53191 \\
$5-6$ & - & 0.26923 & 0.41489 & 0.57909 & 0.49600 \\
$6-7$ & - & 0.42857 & 0.33333 & 0.51389 & 0.46774 \\
$7-8$ & - & 0.33333 & 0.30769 & 0.48649 & 0.44828 \\
$8-9$ & - & - & 0.25000 & 0.50000 & 0.46154 \\
$9-10+$ & - & - & - & 0.25926 & 0.33333 \\
\hline
\end{tabular}

Source: Ministry of Health (MoH), Nepal; New ERA; and ICF. (2017). Calculated by the author from Table 5.4, Nepal Demographic and Health Survey 2016.

As for the currently married women of all reproductive ages (15-49), the PPR from fourth to fifth birth is 53 per cent (it was $65 \%$ in $2001,63 \%$ in 2006 and $55 \%$ in 2011) and it is still more than 40 per cent between the rests of all higher order births of the cohort. Thus, the data on PPRs suggest that there is still higher probability of having higher order of births for different age cohorts of currently married women in Nepal, but it is declining over times. 


\section{Parity progression ratios of all women}

The patterns of parity progression ratios of all women do not differ much from that of currently married women. The probability of having fifth birth for those who have already had fourth for the birth cohort of age group 45-49 years is more than 64 per cent in Nepal in 2016 (Table 2). The corresponding figures were 83 per cent, 80 per cent and 70 per cent in the years 2001, 2006 and 2011 respectively. For the birth cohort of age group 20-24 years, PPR from 1-2 birth is found to be 0.3980 , i.e. about 40 per cent of them are expecting their second birth in the near future at early ages of 20-24 years(it was $62 \%$ in 2001, 55\% in 2006 and $49 \%$ in 2011).

For women of age group 25-29 years, PPR from 2-3 birth is 0.4393 and PPR from 3-4 birth for age group 30-34 years is 0.4766. That is, about 44 per cent in age group 25-29 and 48 per cent in age group 30-34 are likely to have their third and fourth births respectively. The corresponding figures for former birth cohort were 68 per cent, 56 per cent and 50 per cent in the years 2001, 2006 and 2011 respectively; and for latter birth cohort 71 per cent, 58 per cent and 50 per cent in the years 2001, 2006 and 2011 respectively.

Table 2: Parity progression ratios of different birth cohorts (age groups) for all women, Nepal, 2016

\begin{tabular}{|llllll|}
\hline $\begin{array}{l}\text { Parity pro- } \\
\text { gression }\end{array}$ & \multicolumn{5}{l}{$\begin{array}{l}\text { Parity progression ratios of age groups } \\
\text { 20-24 }\end{array}$} \\
& $\begin{array}{l}\text { Birth cohorts } \\
\text { 1991-96 }\end{array}$ & $1986-91$ & $1981-86$ & $1966-71$ & $1966-2001$ \\
\hline $0-1$ & 0.59300 & 0.86300 & 0.95095 & 0.97297 & 0.71371 \\
\hline $1-2$ & 0.39798 & 0.70684 & 0.86000 & 0.96605 & 0.77419 \\
\hline $2-3$ & 0.25000 & 0.43934 & 0.54957 & 0.85410 & 0.60688 \\
\hline-4 & 0.15254 & 0.34328 & 0.47661 & 0.68703 & 0.55522 \\
\hline $4-5$ & 0.22222 & 0.25000 & 0.42056 & 0.64610 & 0.52688 \\
\hline $5-6$ & - & 0.26087 & 0.42222 & 0.58989 & 0.50000 \\
$6-7$ & - & 0.33333 & 0.34211 & 0.50476 & 0.44898 \\
\hline $7-8$ & - & 0.50000 & 0.30769 & 0.49057 & 0.40909 \\
\hline $8-9$ & - & - & 0.25000 & 0.50000 & 0.44444 \\
\hline $9-10+$ & - & - & - & 0.30769 & 0.25000 \\
\hline
\end{tabular}

Source: Same as in Table 1.

Likewise, for all women of all reproductive ages (15-49), the patterns of PPRs are similar to that of currently married women. The PPR from $4-5$ birth is about 53 per cent (it was $65 \%$ in $2001,64 \%$ in 2006 and $56 \%$ in 2011) and more than 40 per cent between the rests of all higher order births of the cohort. The data on PPRs for all women also suggest that although the level of cohort fertility is still higher in Nepal, there is gradual decline over 
times. Analyses of fertility based on parity progression ratios for different birth cohorts show higher probability of having higher order of births as increase in age group for both currently married and all women (Figure 1).
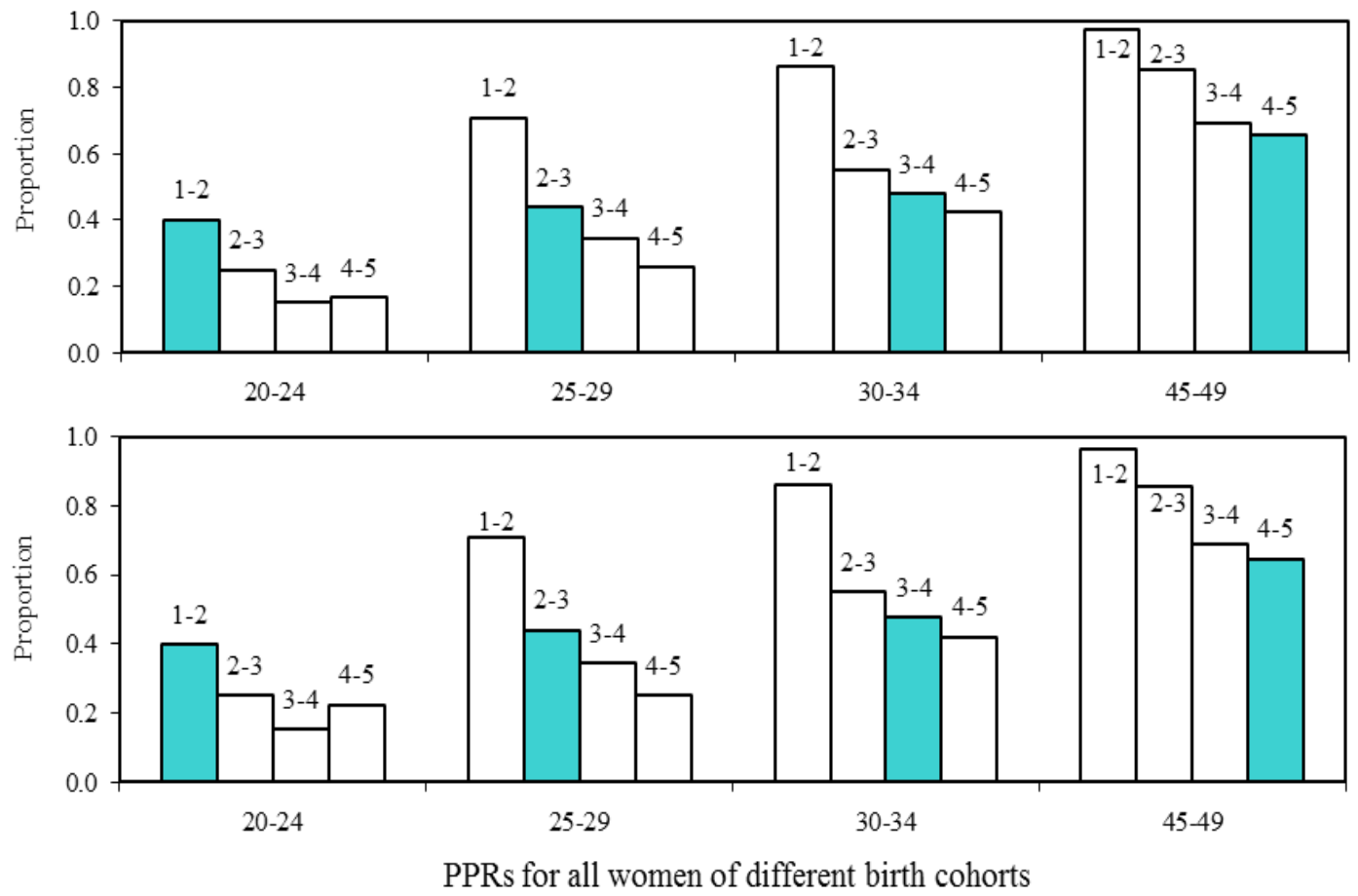

\section{Women with at Least ' $N$ ' Number of Children Ever Born}

The proportion of women having at least ' $N$ ' number of children ever born (CEB) by birth cohorts (age groups) also help to examine the levels and patterns of cohort fertility. Therefore, the proportions of women having at least ' $N$ ' number of CEB are also estimated in this study for currently married women and all women separately by different age groups based on data on parity progression ratios from 2016 Nepal Demographic and Health Survey. The proportions are also analyzed for most fertile three age groups of 20-24, 25-29 and 30-34 years, the last age group of reproductive period (45-49) and for all reproductive ages (15-49) as in parity progression ratios carried out earlier.

\section{At least ' $N$ ' number of CEB and currently married women}

The proportion of currently married women aged 45-49 years with at least 4 children ever born (CEB) is 57 per cent (it was $84 \%$ in 2001, 80\% in 2006 and 67\% in 2011). It denotes that more than half of currently married women in birth cohort of age group 45-49 have 4 or more CEB. Thus, the majority of them already had 4 or more CEB and may add a few by the end of the reproductive period. 
Similarly, the proportions for birth cohort of age group 20-24 years with at least one and two CEB are 79 and 32 per cent respectively (Table 3 ). It represents that nearly eight-in-ten of them already have one or more CEB (it was $85 \%$ in 2001, 87\% in 2006 and $79 \%$ in 2011) and about one-third already have 2 or more CEB (it was 53\% in 2001, 48\% in 2006 and $39 \%$ in 2011) at an early age group of 20-24 years indicating probability of higher cohort fertility.

Table 3: Proportions of currently married women with at least ' $N$ ' number of children ever born for different birth cohorts (age groups), Nepal, 2016

\begin{tabular}{llllll|}
\hline $\begin{array}{l}\text { At least 'N' } \\
\text { no. of }\end{array}$ chil- $20-24$ & $25-29$ & $30-34$ & $45-49$ & $15-49$ \\
dren & ever & Birth cohorts & & & \\
born & $1991-96$ & $1986-91$ & $1981-86$ & $1966-71$ & $1966-2001$ \\
\hline 1 & 0.78700 & 0.92807 & 0.97700 & 0.98800 & 0.90110 \\
2 & 0.31600 & 0.65734 & 0.84100 & 0.96100 & 0.69630 \\
3 & 0.07900 & 0.28871 & 0.46400 & 0.82000 & 0.42258 \\
4 & 0.01200 & 0.09990 & 0.22200 & 0.56900 & 0.23477 \\
\hline 5 & 0.00200 & 0.02597 & 0.09400 & 0.37300 & 0.12488 \\
6 & - & 0.00699 & 0.03900 & 0.21600 & 0.06194 \\
\hline 7 & - & 0.00300 & 0.01300 & 0.11100 & 0.02897 \\
8 & - & 0.00100 & 0.00400 & 0.05400 & 0.01299 \\
9 & - & - & 0.00100 & 0.02700 & 0.00599 \\
$10+$ & - & - & - & 0.00700 & 0.00200 \\
\hline
\end{tabular}

Source: Calculated from parity progression ratios in Table 1.

Likewise, the proportions for age group 25-29 years with at least 2 and 3 CEB are 66 and 29 per cent respectively representing two-third of them already having 2 or more CEB and about one-third having 3 or more CEB at age of below 30 years. The corresponding figures were 87 per cent in 2001, 82 per cent in 2006 and 73 per cent in 2011 for 2 or more CEB; and 59 per cent in 2001, 46 per cent in 2006 and 36 per cent in 2011 for 3 or more CEB. The proportions with at least 3 and 4 CEB for age group 30-34 are about 46 and 22 per cent respectively. That is, a little less than half of them already have 3 or more CEB in that birth cohort. The corresponding figures were 79 per cent in 2001, 70 per cent in 2006 and 54 per cent in 2011 for 3 or more CEB; and 56 per cent in 2001, 41 per cent in 2006 and 27 per cent in 2011 for 4 or more CEB indicating gradual declining trends. These imply that all the birth cohorts of early and middle age groups of the reproductive period are experiencing a bit high fertility and heading towards higher level of completed cohort fertility, even though the level is declining over times.

For all reproductive ages (15-49) also, the proportions with at least 'N' number of CEB are also presented in Table 3 . The levels and patterns in proportion of currently married women with at least "N" number of CEB are not suggesting substantial decline in cohort fertility in Nepal. 


\section{At least ' $N$ ' number of $\mathrm{CEB}$ and all women}

More than 55 per cent of all women aged 45-49 years already have 4 or more CEB in Nepal in 2016 and it is 36 and 21 per cent having 5 or more, and 6 or more CEB respectively for the same birth cohort. The corresponding figures were 80 per cent in 2001, 76 per cent in 2006 and 65 per cent in 2011 for 4 or more CEB. The proportion for birth cohort of age group 2024 years having one or more CEB is about 59 per cent andit is 24 per cent for the same cohort having 2 or more CEB (Table 4). Likewise for age group 25-29 years, the proportion is 61 and 27 per cent for women with at least 2 and 3 CEB respectively. At age group 30-34 years, the proportion is 45 and 21 per cent for having at least 3 and 4 CEB respectively.

Table 4: Proportions of all women with at least ' $N$ ' number of children ever born for different birth cohorts (age groups), Nepal, 2016

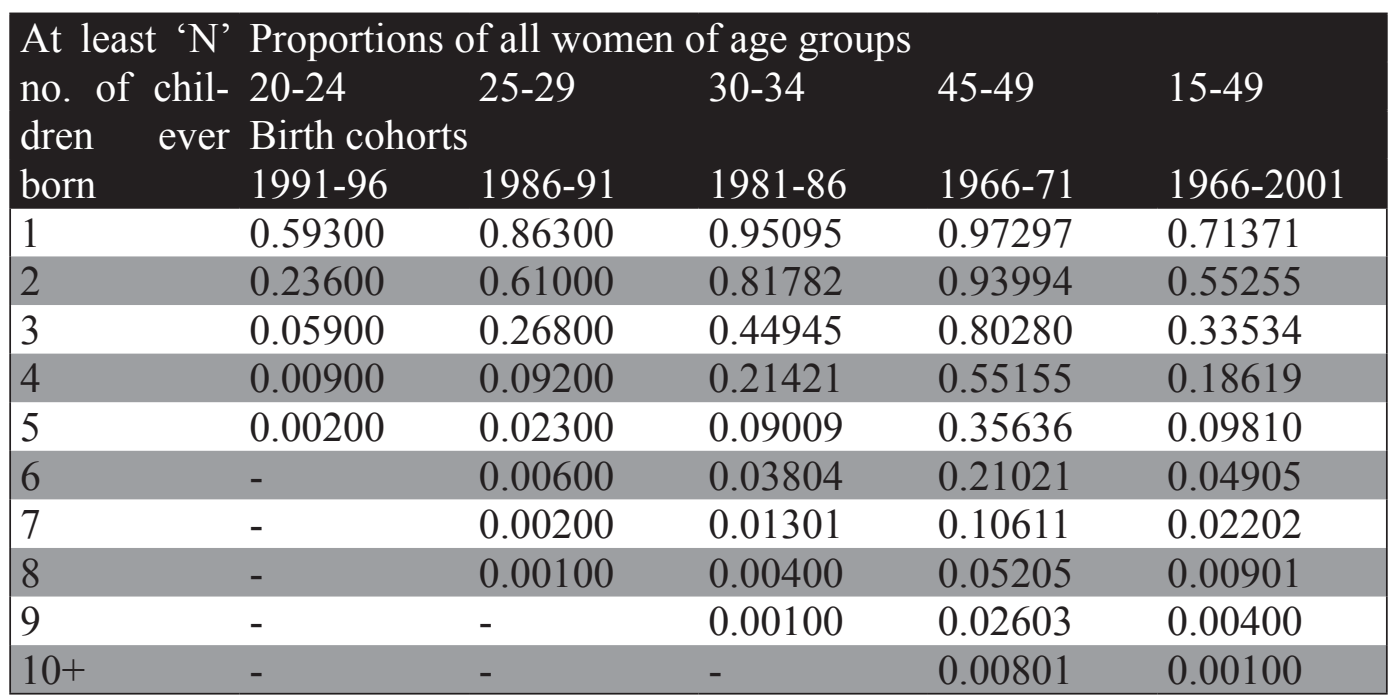

Source: Calculated from parity progression ratios in Table 2.

The proportions of all women of all reproductive ages (15-49) are 19 and 10 per cent having 4 or more, and 5 or more CEB in 2016. The proportions of all women with at least ' $N$ ' number of CEB in each birth cohort is slightly lower as compared to that with currently married women of corresponding birth cohorts, but the patterns are similar in the both the cases.

\section{Cohort Fertility Rates}

\section{Cohort fertility rate of women aged $45-49$ years}

Based on data of parity progression ratios obtained from 2001 to 2016 Nepal Demographic and Health Surveys, the estimates of cohort fertility for birth cohort 
of age group 45-49 years at the time of surveys are presented in Table 5. The cohort fertility rate of currently married women of age group 45-49 years is estimated at 4.1 , which will be close to the completed cohort fertility of that cohort. It is gradually declined from 5.9 in 2001 to 5.5 in 2006 to 4.6 in 2011 to 4.1 in 2016, a decline of 1.7 children over the period of 15 years.

Similarly, the cohort fertility rate of all women of the same birth cohort of age group $45-49$ years is found to be 4.0, which will be slightly higher than this value by the end of the reproductive ages and it is higher by almost 2 than the synthetic total fertility rate of 2.3 of all women in 2016.

Table 5: Cohort fertility rates of currently married women and all women of birth cohort of age group 45-49 years, Nepal, 2016

\begin{tabular}{|lll|}
\hline \multicolumn{1}{l}{ Surveys } & Birth cohort & Cohort fertility rate (45-49 years) \\
\hline Currently married women & & \\
\hline 2016 NDHS & $1966-71$ & 4.13 \\
2011 NDHS & $1961-66$ & 4.55 \\
\hline 2006 NDHS & $1956-61$ & 5.48 \\
2001 NDHS & $1951-56$ & 5.87 \\
\hline All women & & \\
\hline 2016 NDHS & $1966-71$ & 4.03 \\
2011 NDHS & $1961-66$ & 4.69 \\
2006 NDHS & $1956-61$ & 5.23 \\
\hline 2001 NDHS & $1951-56$ & 5.64 \\
\hline
\end{tabular}

Sources: Calculated by the author from parity progression ratios in Tables 1 and 2 for the year 2016; calculated similarly for the years 2011 and 2006from relevant tables from MoHP et al. (2012, 2007); and Shakya (2006) for the year 2001.

\section{Conclusions}

Fertility analyses based on parity progression ratios for different birth cohorts show higher probability of having higher order of births as increase in age group for both currently married and all women. Two-thirds currently married women of age group 45-49 years have probability of having fifth birth for those who have already had fourth. Among the birth cohort of age group 20-24 years, two-fifths are going to have their second birth in the near future at these early ages and more than two-fifths in age group 25-29 years have probability of second to third birth for. Similarly, almost half in age group 30-34 have probability of third to fourth birth. The patterns of PPRs are almost similar for all women but with slightly lower level of ratios. 
The PPRs also provide proportion of women with at least ' $\mathrm{N}$ ' number of CEB and the fertility analysis in this way also indicates a bit higher level of fertility in Nepal. Currently married women of birth cohort of age group 45-49 years with at least 4 CEB isnearly threefifths. Similarly, the birth cohort of age group 20-24 years with at least one CEB are fourfifths and one-third already have two or more CEB in this early age group of childbearing. Likewise, the birth cohort of age group 25-29 years with at least 2 and 3 CEB are two-thirds and slightly less than one-third respectively. Nearly one-half of currently married women in cohort of age group 30-34 years have already 3 or more CEB. The patterns of data are almost similar for all women as well.

Parity progression ratios can also facilitate to estimate cohort fertility rates and these measures also represent somewhat high fertility in Nepal. The cohort fertility rate for birth cohort of age group 45-49 years among currently married women is found to be 4.1 and the cohort fertility rate of all women of the same birth cohort is 4.0. All these findings suggest that cohort fertility in Nepal is still at somewhat higher level and it is declining only gradually over the time unlike rapid decline observed in period fertility measures.

\section{References}

Ministry of Health (MoH), Nepal; New ERA; and ICF.(2017).Nepal demographic and health survey 2016. Kathmandu: $\mathrm{MoH}$.

Ministry of Health and Population (MoHP) [Nepal]; New ERA; and ICF International Inc. (2012). Nepal demographic and health survey 2011. Kathmandu, Nepal: MoHP, New ERA, and ICF International Inc.

Ministry of Health and Population (MoHP) [Nepal]; New ERA; and Macro International Inc. (2007). Nepal demographic and health survey 2006. Kathmandu, Nepal: MoHP, New ERA, and Macro International Inc.

Moultrie, T.A., \& Zaba, B. (2013). Parity progression ratio. In Moultrie, T.A., Dorrington, R.E., Hill, A.G., Hill, K., Timaeus, I.M., \& Zaba, B. (eds.). Tools for demographic estimation. Paris: International Union for the Scientific Study of Population, 69-81.

Newell, C.(1988).Methods and models in demography. New York: The Guilford Press.

Population Reference Bureau (PRB).(2001).Population handbook, $4^{\text {th }}$ Edition. Washington, DC: PRB.

Shakya, D.V. (2006). Parity progression ratio analysis of cohort fertility in Nepal, 2001. Nepal Population Journal, 12 (11): 59-68.

Shryock, H.S., Jacob S.S.,\& et al. (1976).The methods and materials of demography. Condensed edition by Edward G.S. (ed.). New York: Academic Press.

Sloggett, A. (2015). Measuring fertility. Population analysis in policy and programs. Paris: International Union for the Scientific Study of Population. Retrieved from http://papp.iussp. org/sessions/papp101_s04/PAPP101_s04_010_010.html. Accessed on 2020-08-30. 